\title{
Study on Mechanical Properties and Energy Dissipation of Frozen Sandstone under Shock Loading
}

\author{
Lei Wang $\mathbb{D}^{1},{ }^{1}$ Yue Qin $\mathbb{D}^{1},{ }^{1}$ Haibin Jia, ${ }^{2}$ Hongming Su $\mathbb{D},{ }^{1}$ and Shiguan Chen ${ }^{1}$ \\ ${ }^{1}$ College of Architecture and Civil Engineering, Xi'an University of Science and Technology, Xi'an, Shaanxi 710054, China \\ ${ }^{2}$ Shandong Xinjulong Energy Co. Ltd., Heze, Shandong 274000, China \\ Correspondence should be addressed to Yue Qin; qy1126442374@163.com
}

Received 25 June 2020; Revised 25 August 2020; Accepted 7 October 2020; Published 2 November 2020

Academic Editor: Xianjie Hao

Copyright (c) 2020 Lei Wang et al. This is an open access article distributed under the Creative Commons Attribution License, which permits unrestricted use, distribution, and reproduction in any medium, provided the original work is properly cited.

In order to understand the mechanical properties and energy dissipation law of frozen sandstone under impact loading, the cretaceous water-rich red sandstone was selected as the research object to conduct impact tests at different freezing temperatures $\left(0^{\circ} \mathrm{C},-10^{\circ} \mathrm{C}\right.$, $-20^{\circ} \mathrm{C}$, and $-30^{\circ} \mathrm{C}$ ). The test results suggested the following: (1) the peak stress and peak strain of frozen sandstone are positively correlated with strain rate and freezing temperature, and the strain rate strengthening effect and the low-temperature hardening effect are obvious. (2) The strain rate sensitivity of dynamic stress increase factor (DIF) is negatively correlated with temperature. Water-ice phase change and the difference in the cold shrinkage rate of rock matrix under strong impact loading will degrade the performance of rock together, so DIF is less than 1. (3) In the negative temperature range from $-10^{\circ} \mathrm{C}$ to $-30^{\circ} \mathrm{C}$, DEIF is always greater than 1 . The energy dissipation rate of red sandstone specimens fluctuated between $10 \%$ and $25 \%$ under the impact loading, and the data are discrete, showing obvious strain rate independence. The failure form changes from tensile failure to shear and particle crushing failure. (4) Combined with the micromechanism analysis, the difference in dynamic mechanical properties of red sandstone at different temperatures is caused by the water-ice phase change and the different cold shrinkage rates of the frozen rock medium. When the temperature drops from $0^{\circ} \mathrm{C}$ to $-2^{\circ} \mathrm{C}$, water migrates to the free space of the pore of frozen rock and freezes into ice crystal, resulting in frozen shrinkage. At $-30^{\circ} \mathrm{C}$, the expansion of ice dominates and the migration of water will stop, leading to frost heave.

\section{Introduction}

The cretaceous weakly cemented soft rock is a type of special rock widely distributed in mines in western China, which has obvious mechanical characteristics of low strength, poor cementation, easy hydrolysis, and easy weathering. In order to avoid the influence of the underground water on the construction environment and the quality of the shaft wall in the mine construction, the freezing method has become the best scheme for the construction of the vertical shaft in the water-rich soft rock stratum. However, during the process of freezing shaft sinking in this type of stratum, the frozen wall is often destabilized and damaged due to blasting impact loading, leading to the occurrence of water seepage, water gushing, and other accidents, which seriously affect the construction progress of vertical shaft and the safety of coal mine production. Therefore, it is necessary to study the dynamic characteristics of this type of rock under lowtemperature freezing conditions.

So far, many scholars have carried out a lot of research on Cretaceous soft rock from different perspectives. Yang et al. [1-4] conducted a systematic study on the static characteristics of Cretaceous water-rich soft rock in western China and pointed out that the strength and softening coefficient of this type of soft rock are low in the unfrozen state, but the compressive strength and elastic modulus increase with the decrease in temperature in the frozen state. Wang and Zhao et al. [5-8] studied the damage behavior of such soft rocks under a complex stress state through the triaxial compression test and principle of equivalent strain, obtained the evolution law of damage variable of sandstone under triaxial compression, and established the statistical damage constitutive model considering the residual stage deformation of argillaceous sandstone. Liu et al. [9-11] 
considered the coupling effect of temperature field and geostress field on the frozen wall rock mass in the freezing construction of shaft in the Western region, and triaxial tests of red sandstone at different freezing temperatures and confining pressures were carried out and pointed out that the effect of geostress enhanced the ability of pore restriction and resistance to frost heave deformation so that the freezing effect could develop to the secondary micropores as much as possible. Chen et al. [12] carried out an experimental study on the physical and mechanical properties, water softening characteristics, and mechanism of energy damage evolution of Cretaceous argillaceous sandstone and pointed out that rock is dominated by circumference deformation and volume expansion under low confining pressure. However, with the increase in confining pressure, the failure form changes from volume expansion to volume compression, and the damage evolution process presents an S-shaped change rule. Shen et al. [13, 14] discussed the cause of damage characteristics and thermophysical properties difference of sandstone at different temperatures. Zhao et al. [15] carried out research on red sandstone specimens to investigate their short-term and creep mechanical behavior under incremental cyclic compressive and tensile loading. Sun et al. [16] studied the mechanical response characteristics of sandstone specimens under different stress amplitudes and loading frequencies by a TAW-2000 rock triaxial testing machine. It can be seen that this type of soft rock has been studied comprehensively in statics.

In terms of dynamics, since the SHPB system was introduced into China, relevant scholars have conducted a lot of research on the dynamic properties of rock materials. $\mathrm{Li}$ et al. [17-19] used the SHPB device to carry out uniaxial and triaxial impact tests on sandstone in different states and analyzed its mechanical properties, damage rules, and failure modes. Liu et al. [20,21] carried out cyclic impact tests under different confining pressures on sandstone specimens. Ultrasonic waves were used to detect impact damage and analyzed the relationship between longitudinal wave velocity and stress-strain of sandstone. Ma and Yuan et al. [22-24] studied the mechanical properties and failure laws of filled weakly jointed sandstone with different dip angles under impact loading and captured the crack propagation and dynamic failure process in real time with the help of highspeed photography. For the study of water-rich soft rock of Cretaceous under the coupling effect of freezing field and impact field, Yang and Yang et al. [25-27] applied the SHPB system and combined with the SEM scanning experiment to analyze the change trend of dynamic strength of sandstone with temperature and explored the microfracture mechanism of water-saturated frozen red sandstone. Shan et al. [26-30] studied the dynamic mechanical properties of Cretaceous red sandstone in a frozen state and established the corresponding damage constitutive model. Du et al. [31] conducted dynamic impact tests on red sandstone specimens with different times of dry-wet cycles. The changes in relevant physical and mechanical parameters indicated that dry-wet cycles would lead to the performance degradation of red sandstone. In addition, with the rapid development of computer technology, the numerical method has gradually become a very effective means to study the rock impact damage process and analyze the damage mechanism $[32,33]$. Based on this, the attenuation function model was established to predict the dynamic compressive strength change in red sandstone.

On the basis of the above research results, this study takes the Cretaceous water-rich and weakly cemented red sandstone encountered in the process of freezing shaft sinking in Wuju coal mine of Gansu Province as the research object and studies its dynamic mechanical characteristics under different freezing temperatures $\left(0^{\circ} \mathrm{C},-10^{\circ} \mathrm{C},-20^{\circ} \mathrm{C}\right.$, and $\left.-30^{\circ} \mathrm{C}\right)$. The corresponding research results can provide guidance and supplement for the construction of coal mine shaft and the development of geotechnical engineering theory in cold areas.

\section{Test Equipment and Scheme}

2.1. Specimen Preparation. Based on Wuju coal mine in Gansu Province, the Cretaceous water-rich and weakly consolidated red sandstone encountered during the process of freezing shaft sinking is selected as the research object. The rock specimens are reddish brown with uniform surface lithology. The main mineral components are quartz (48.9\%), plagioclase $(22.9 \%)$, potash feldspar $(10.7 \%)$, calcite $(6 \%)$, and montmorillonite (6\%). The main chemical composition content measured by X-ray instrument is shown in Figure 1.

According to the test scheme, the rock is processed into a standard cylinder specimen with a diameter of $50 \mathrm{~mm}$ and a height of $25 \mathrm{~mm}$ through drilling, cutting, grinding, and other processes, and the end face and axial nonparallelism of the specimen are controlled within $0.02 \mathrm{~mm}$. In order to reduce the discreteness of physical and mechanical properties, some specimens with large differences were first eliminated visually. Then, with the assistant of oven and ultrasonic velocimeter, specimens with similar dry density and wave velocity were selected for testing. The average values of basic physical and mechanical parameters of the specimens are shown in Table 1.

To achieve the purpose of full water saturation, the specimens were first baked in a high-temperature cabinet at $105^{\circ} \mathrm{C}$ for $24 \mathrm{~h}$ and then wet pumped for $4 \mathrm{~h}$ after dry pumping for $6 \mathrm{~h}$ in a vacuum saturation device with a constant negative pressure of $0.1 \mathrm{MPa}$ and soaked continuously under natural conditions for more than $48 \mathrm{~h}$ finally. The saturated specimens were coated with vaseline and wrapped with plastic wrap and then placed in a low-temperature box and cooled slowly at a constant cooling rate of $0.02^{\circ} \mathrm{C} / \mathrm{min}$. After reaching the set temperature, it is kept stable for more than $48 \mathrm{~h}$ to obtain the frozen specimens.

2.2. SHPB Device and Working Principle. The dynamic impact test was conducted in the Impact Dynamics Laboratory of Xi'an University of Science and Technology. The structure composition of the split Hopkinson pressure bar system is shown in Figure 2. The device is mainly composed of five parts: loading drive system, pressure bar system, energy absorption system, signal acquisition system, and signal 


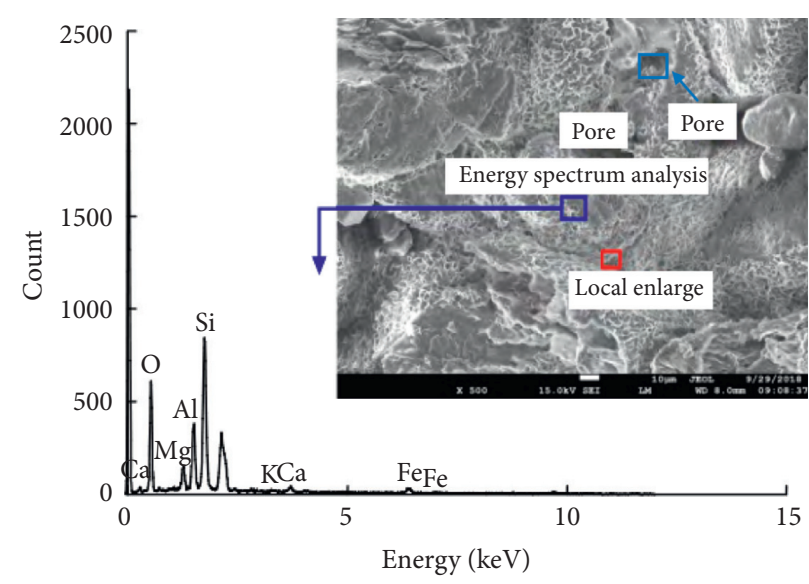

Figure 1: Sandstone XRD diffraction pattern.

TABLE 1: Average physical and mechanical parameters of sandstone.

\begin{tabular}{lccccc}
\hline $\begin{array}{l}\text { Longitudinal wave velocity } \\
(\mathrm{m} / \mathrm{s})\end{array}$ & $\begin{array}{c}\text { Dry density } \\
\left(\mathrm{g} / \mathrm{cm}^{3}\right)\end{array}$ & $\begin{array}{c}\text { Saturated density } \\
\left(\mathrm{g} / \mathrm{cm}^{3}\right)\end{array}$ & $\begin{array}{c}\text { Elasticity modulus } \\
(\mathrm{GPa})\end{array}$ & $\begin{array}{c}\text { Porosity } \\
(\%)\end{array}$ & $\begin{array}{c}\text { Uniaxial compressive strength } \\
(\mathrm{MPa})\end{array}$ \\
\hline 1897 & 1874 & 2182 & 1.217 & 25.8 & 13.78 \\
\hline
\end{tabular}

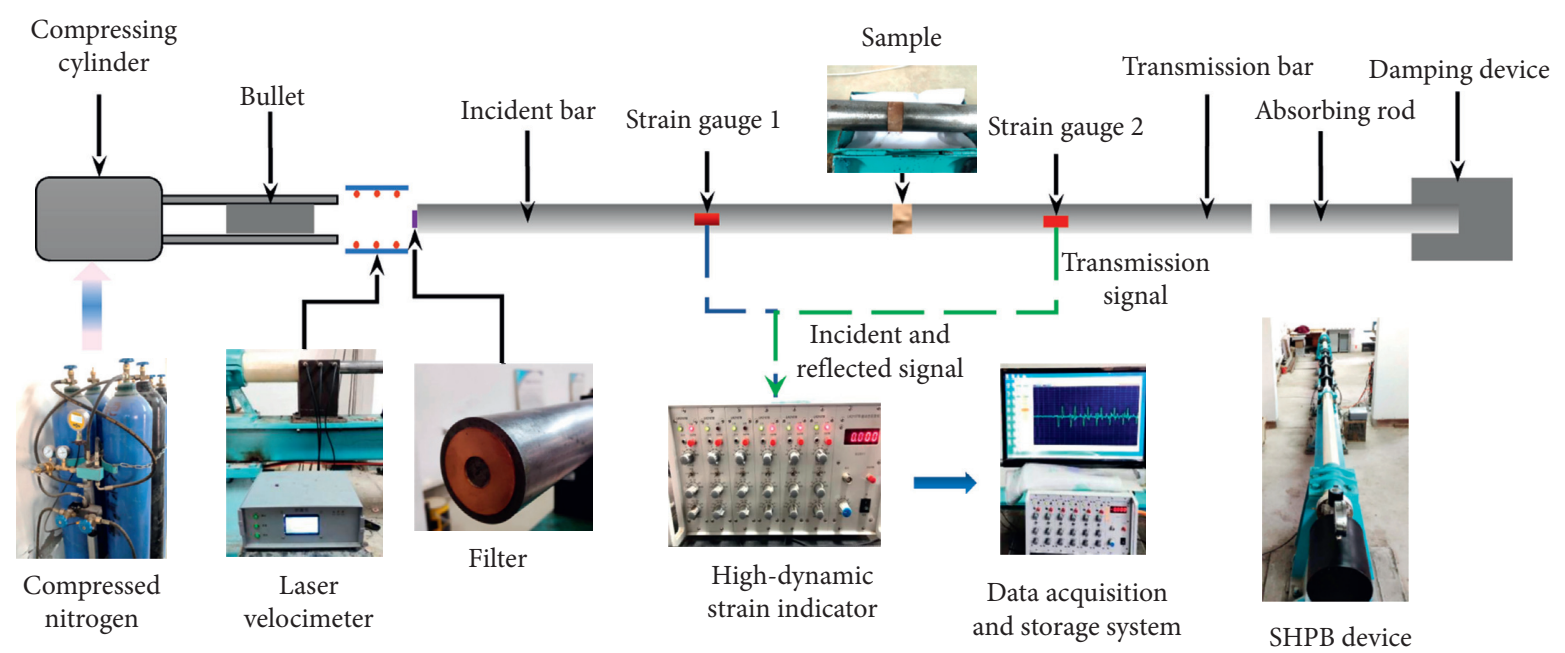

Figure 2: Structure composition of SHPB system.

processing system. The bar system is made of high-strength alloy steel, in which the bullet length is $300 \mathrm{~mm}$, the incident bar length is $3700 \mathrm{~mm}$, the transmitted bar length is $2500 \mathrm{~mm}$, the elastic modulus is $210 \mathrm{GPa}$, the density is $7800 \mathrm{~kg} / \mathrm{m}^{3}$, and the theoretical wave velocity is $5172 \mathrm{~m} / \mathrm{s}$.

The theory of elastic stress wave propagation is the basic working principle of SHPB system, which is mainly based on two hypotheses: (1) one-dimensional elastic deformation hypothesis: the propagation of stress wave in the whole bar system is one-dimensional elastic, and there is no dispersion phenomenon occurring in the propagation process, which can ensure that the stress wave at the test point on the bar is truly inverted to the end face of the specimen and the pressure bar; (2) stress uniformity hypothesis: stress and strain are uniformly distributed along the length of the specimen, and the specimen is uniformly deformed under impact.

In the impact test, the frozen specimen is clamped between the incident bar and the transmitted bar. The instant release of high-pressure nitrogen will promote the bullet to move forward at high speed until it collides with the incident bar. So the incident pulse is generated in the incident bar and propagates forward. When the incident bar hits the specimen and causes the specimen to deform at high speed, the stress pulse will be reflected and transmitted multiple times at the interface between the specimen and the pressure bar. Some of the pulse will be reflected, and the other parts will enter the transmitted bar through the specimen. Through the strain gauges on the elastic compression bar, each signal can be recorded into the signal acquisition system. 
Under the condition that the two end faces of the specimen meet the assumptions of stress balance and uniformity, the collected signals can be calculated by the threewave method formula to obtain the dynamic mechanical parameters of the specimen:

$$
\begin{aligned}
& \sigma(t)=\frac{A_{0} E}{2 A}\left(\varepsilon_{I}+\varepsilon_{R}+\varepsilon_{T}\right), \\
& \mathcal{\varepsilon}(t)=\frac{C}{L} \int_{0}^{t} E\left(\varepsilon_{I}+\varepsilon_{R}+\varepsilon_{T}\right) \mathrm{d} t, \\
& \dot{\varepsilon}(t)=\frac{C}{L}\left(\varepsilon_{I}-\varepsilon_{R}-\varepsilon_{T}\right),
\end{aligned}
$$

where $A_{0}$ and $A$ are the section area of specimen and the pressure bar, respectively $\left(\mathrm{m}^{2}\right) ; E$ is the elasticity modulus of pressure bar $(\mathrm{GPa}) ; C$ is the longitudinal wave velocity of the pressure bar $(\mathrm{m} / \mathrm{s})$; $L$ represents the thickness of the specimen $(\mathrm{m}) ; \varepsilon_{I}, \varepsilon_{R}$, and $\varepsilon_{T}$ represent the incident strain, reflected strain, and transmitted strain of the bars, respectively; and $\sigma, \varepsilon$, and $\dot{\varepsilon}$ are stress, strain $(\mathrm{MPa})$, and strain rate $\left(\mathrm{s}^{-1}\right)$, respectively.

2.3. Test Scheme. According to the actual distribution of the temperature field of vertical shaft during the process of freezing shaft sinking, the specimens are divided into four groups according to different freezing temperatures $\left(0^{\circ} \mathrm{C}\right.$, $-10^{\circ} \mathrm{C},-20^{\circ} \mathrm{C}$, and $-30^{\circ} \mathrm{C}$ ), and each group has five specimens at least. The frozen specimens should be transferred to the SHPB device immediately to complete the uniaxial impact test. The impact loading applied is determined according to the actual monitoring data, and the corresponding bullet speeds are $3.0 \mathrm{~m} / \mathrm{s}, 3.5 \mathrm{~m} / \mathrm{s}, 4.0 \mathrm{~m} / \mathrm{s}, 4.5 \mathrm{~m} / \mathrm{s}$, and $5.0 \mathrm{~m} / \mathrm{s}$.

The average values of the test results are taken after the individual data with large discreteness are removed [34], and the dynamic mechanical parameters of saturated frozen red sandstone under different impact velocities are shown in Table 2 .

\section{Test Results and Analysis}

3.1. Peak Stress Analysis. According to the test data, the relationship between peak stress and strain rate of saturated red sandstone under different freezing temperatures is plotted, as shown in Figure 3.

It can be seen that the peak stress of frozen sandstone increases linearly with the increase in strain rate, and the effect of strain rate is obvious. In the same range of strain rate, the peak stress of specimen increases gradually with the decrease in temperature, and the low-temperature hardening effect is significant. The difference in peak stress of each temperature specimen decreases gradually with the increase in strain rate. When the incident bar strikes the specimen at a speed of $5 \mathrm{~m} / \mathrm{s}$, the peak stress of specimen at $-30^{\circ} \mathrm{C}$ is significantly lower than $-20^{\circ} \mathrm{C}$. In reference to the relevant literature [27], it is mainly related to the "frostbite" under high strain rate.
3.2. Peak Strain Analysis. The deformation capacity of rock under ultimate loading can be measured by peak strain. Figure 4 shows the relationship between peak strain and strain rate of saturated red sandstone under different freezing temperatures. It can be seen that the peak strain also increases linearly with the increase in strain rate, showing a significant correlation with strain rate.

The slope of the fitting curve can represent the strain rate sensitivity. It can be found that the curves slopes of specimens at $0^{\circ} \mathrm{C},-20^{\circ} \mathrm{C}$, and $-30^{\circ} \mathrm{C}$ are close to 0.0042 , indicating that the strain rate sensitivity of the three specimens is basically the same. The strain rate sensitivity of $-10^{\circ} \mathrm{C}$ specimen is significantly lower than other temperature gradients. Different from the change in the peak stress, the peak strain of $-30^{\circ} \mathrm{C}$ specimen is significantly lower than $-20^{\circ} \mathrm{C}$, which is because the temperature is too low at $-30^{\circ} \mathrm{C}$. While the strength of the rock increases, the brittleness appears gradually, resulting in the decrease in deformation value during failure.

3.3. Dynamic Increase Factor (DIF and DEIF). In order to analyze the influence of dynamic loading on the strength and deformation of frozen sandstone, the concepts of dynamic stress increase factor (DIF) and dynamic strain increase factor (DEIF) are introduced. The calculation formulas are as follows:

$$
\begin{array}{r}
\text { DIF }=\frac{\sigma_{d}}{\sigma_{s}}, \\
\text { DEIF }=\frac{\varepsilon_{d}}{\varepsilon_{s}},
\end{array}
$$

where $\sigma_{d}$ and $\varepsilon_{d}$ are dynamic compressive strength and dynamic peak strain, respectively $(\mathrm{MPa})$, and $\sigma_{s}$ and $\varepsilon_{s}$ are static compressive strength $(\mathrm{MPa})$ and static peak strain, respectively. The calculated values of saturated red sandstone at different freezing temperatures are shown in Table 3.

3.4. Dynamic Stress Increase Factor (DIF). Figure 5 shows the relation curve between DIF and strain rate of frozen red sandstone.

It can be seen that the strain rate strengthening effect of DIF is also very significant at different freezing temperatures. The strain rate sensitivity of DIF is negatively related to temperature according to the slope of fitting curve. Taking the DIF value equal to 1 as the distinguishing standard, the curve can be divided into two sections, in which the proportion of DIF less than 1 increases gradually with the decrease in temperature. The reasons are summarized as follows: in the static or quasistatic load test, the internal damage caused by the water-ice phase change and the different cold shrinkage rates of the frozen rock matrix cannot be fully reflected. However, under the action of strong impact loading or stress wave, because the fracture derivation rate is far greater than the fracture closure, the deterioration of the mechanical properties of the rock is fully revealed, and the lower the temperature is, the more obvious the phenomenon is. 
TABle 2: Dynamic mechanical parameters of saturated frozen sandstone under different impact velocities.

\begin{tabular}{|c|c|c|c|c|c|c|c|c|c|}
\hline $\begin{array}{l}\text { Temperature } \\
\left({ }^{\circ} \mathrm{C}\right)\end{array}$ & $\begin{array}{c}\text { Impact } \\
\text { speed }(\mathrm{m} / \mathrm{s})\end{array}$ & $\begin{array}{l}\text { Strain rate } \\
\qquad\left(\mathrm{s}^{-1}\right)\end{array}$ & $\begin{array}{c}\text { Peak stress } \\
(\mathrm{MPa})\end{array}$ & $\begin{array}{c}\text { Peak } \\
\text { strain (\%) }\end{array}$ & $\begin{array}{c}\text { Temperature } \\
\left({ }^{\circ} \mathrm{C}\right)\end{array}$ & $\begin{array}{c}\text { Impact } \\
\text { speed }(\mathrm{m} / \mathrm{s})\end{array}$ & $\begin{array}{l}\text { Strain rate } \\
\qquad\left(\mathrm{s}^{-1}\right)\end{array}$ & $\begin{array}{l}\text { Peak stress } \\
(\mathrm{MPa})\end{array}$ & $\begin{array}{c}\text { Peak } \\
\text { strain (\%) }\end{array}$ \\
\hline \multirow{5}{*}{0} & 3.0 & 115 & 13.1 & 0.58 & \multirow{5}{*}{-10} & 3.0 & 102 & 15.8 & 0.91 \\
\hline & 3.5 & 138 & 17.8 & 0.65 & & 3.5 & 125 & 20 & 0.95 \\
\hline & 4.0 & 160 & 20.5 & 0.72 & & 4.0 & 144 & 25 & 0.98 \\
\hline & 4.5 & 195 & 26.5 & 0.85 & & 4.5 & 185 & 29.5 & 1.01 \\
\hline & 5.0 & 211 & 29.8 & 0.95 & & 5.0 & 210 & 32.2 & 1.03 \\
\hline \multirow{5}{*}{-20} & 3.0 & 98 & 18.5 & 0.89 & \multirow{5}{*}{-30} & 3.0 & 90 & 20.2 & 0.75 \\
\hline & 3.5 & 115 & 22.5 & 0.99 & & 3.5 & 105 & 24.5 & 0.85 \\
\hline & 4.0 & 132 & 25.1 & 1.12 & & 4.0 & 125 & 26.6 & 0.93 \\
\hline & 4.5 & 170 & 30.2 & 1.28 & & 4.5 & 162 & 32.2 & 1.08 \\
\hline & 5.0 & 205 & 36.0 & 1.33 & & 5.0 & 192 & 34.0 & 1.15 \\
\hline
\end{tabular}

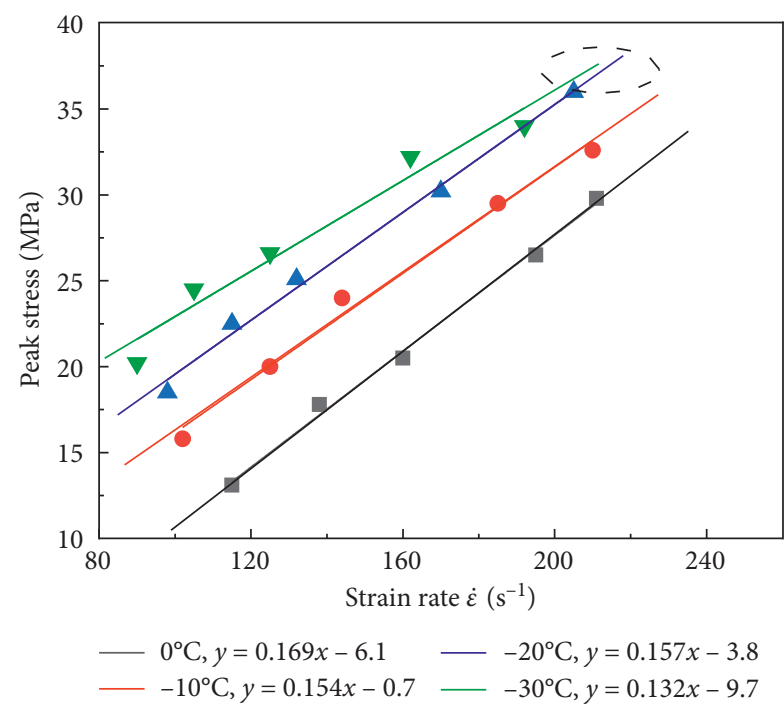

FIGURE 3: Relationship between peak stress and strain rate.

3.5. Dynamic Strain Increase Factor (DEIF). Figure 6 shows the relationship between DEIF and strain rate at different freezing temperatures. It can be found that DEIF increases with the increase in strain rate, and the strain rate strengthening effect is obvious. According to the slope of the fitting curve, the change trend is different. The strain rate sensitivity of $-10^{\circ} \mathrm{C}$ is the lowest, and the sensitivity of $-20^{\circ} \mathrm{C}$ and $-30^{\circ} \mathrm{C}$ specimens is basically the same.

The deformation resistance of the specimen is poor at $0^{\circ} \mathrm{C}$, and failure occurs when the deformation is not sufficient under impact; the dynamic peak strain is smaller than the static peak strain, so DEIF is less than 1 . When the strain rate exceeds $180 \mathrm{~s}^{-1}$, the lateral inertia effect appears gradually under high strain rate, and the increase in lateral restraint shows the specimen has a greater deformation capacity in the axial direction, so DEIF is greater than 1.

Compared with the curves of $-10^{\circ} \mathrm{C},-20^{\circ} \mathrm{C}$, and $-30^{\circ} \mathrm{C}$, low-temperature hardening effect and lateral inertia effect improve the deformation resistance of the specimen together, so the value of DEIF is always greater than 1 . The slope of the curve at $-10^{\circ} \mathrm{C}$ is significantly lower than other temperature gradients, and the strain rate sensitivity is the lowest. The specimens suffer from "frostbite" at $-30^{\circ} \mathrm{C}$, and the overall deformation ability

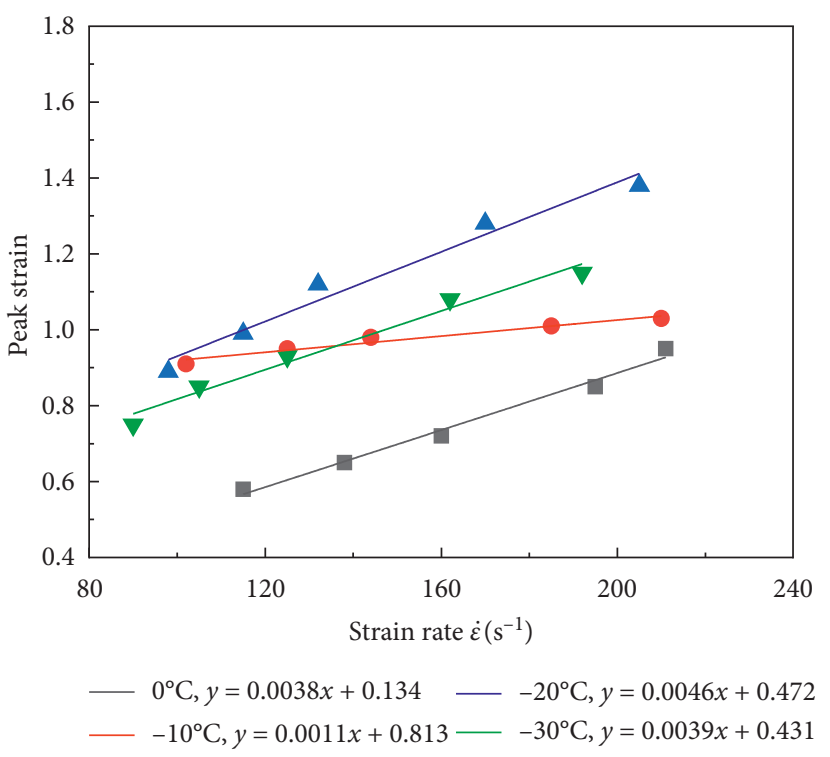

FIGURE 4: Relationship between peak strain and strain rate.

decreases. So the corresponding value of DEIF is decreased to a certain extent compared with the specimen at $-20^{\circ} \mathrm{C}$, but the overall change trend remained the same.

\section{Energy Transfer Law and Dissipation Characteristics}

4.1. Energy Calculation. According to the basic theory of stress wave, the energy carried by the stress wave in the process of rock impact failure can be calculated according to the following formula:

$$
\left\{\begin{array}{l}
W_{I}=\operatorname{AEC} \int \varepsilon_{I}^{2} \mathrm{~d} t \\
W_{R}=\operatorname{AEC} \int \varepsilon_{R}^{2} \mathrm{~d} t \\
W_{T}=\operatorname{AEC} \int \varepsilon_{T}^{2} \mathrm{~d} t
\end{array}\right.
$$

where $A, E$, and $C$ are the section area $\left(\mathrm{m}^{2}\right)$, elastic modulus $(\mathrm{GPa})$, and longitudinal wave velocity $(\mathrm{m} / \mathrm{s})$ of the pressure bar, respectively; $\varepsilon_{I}, \varepsilon_{R}$, and $\varepsilon_{T}$ are incident strain, reflected 
TABLE 3: DIF and DEIF values of samples at different frost temperatures.

\begin{tabular}{|c|c|c|c|c|c|c|c|c|c|c|c|}
\hline$T\left({ }^{\circ} \mathrm{C}\right)$ & DIF & DEIF & $T\left({ }^{\circ} \mathrm{C}\right)$ & DIF & DEIF & $T\left({ }^{\circ} \mathrm{C}\right)$ & DIF & DEIF & $T\left({ }^{\circ} \mathrm{C}\right)$ & DIF & DEIF \\
\hline \multirow{5}{*}{0} & 0.94 & 0.72 & \multirow{5}{*}{-10} & 0.63 & 1.42 & \multirow{5}{*}{-20} & 0.63 & 1.42 & \multirow{5}{*}{-30} & 0.51 & 1.39 \\
\hline & 1.28 & 0.80 & & 0.80 & 1.48 & & 0.80 & 1.48 & & 0.61 & 1.57 \\
\hline & 1.46 & 0.89 & & 0.99 & 1.53 & & 0.99 & 1.53 & & 0.66 & 1.72 \\
\hline & 1.91 & 1.05 & & 1.18 & 1.58 & & 1.18 & 1.58 & & 0.80 & 2.00 \\
\hline & 2.14 & 1.17 & & 1.28 & 1.61 & & 1.28 & 1.61 & & 0.84 & 2.13 \\
\hline
\end{tabular}

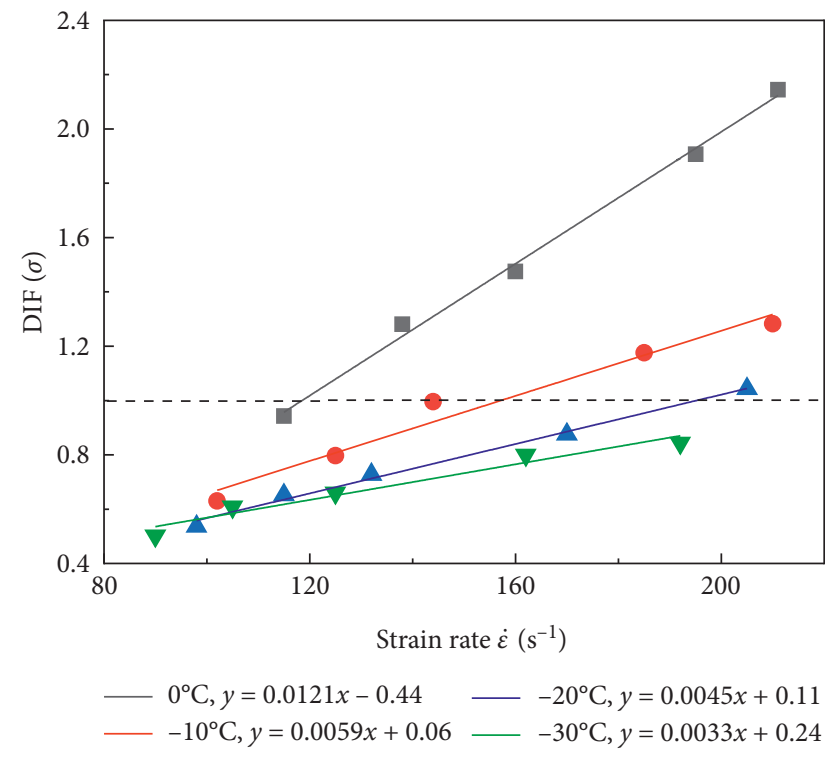

FIgURE 5: Relationship between DIF and strain rate.

strain, and transmitted strain, respectively; and $W_{I}, W_{R}$, and $W_{T}$ represent incident energy $(\mathrm{J})$, reflected energy $(\mathrm{J})$, and transmitted energy, respectively $(\mathrm{J})$.

Assuming that the energy loss at the interface between the elastic pressure bar and the specimen is negligible, the absorbed energy of the specimen in the impact process can be calculated according to the following formula:

$$
W_{L}=W_{I}-W_{R}-W_{T}
$$

where $W_{L}$ is absorbed energy $(\mathrm{J})$, mainly including breakage energy $W_{D}$, fragment ejection kinetic energy $W_{K}$, and other consumption energy $W_{O}$. Assuming that there is no heat exchange between the specimen and the external environment during the impact process, the breakage energy is equal to the absorbed energy.

In order to reflect the energy absorption of rock during the impact process and eliminate the influence of specimen size effect, the specific energy absorption (SEA) value is used to measure the energy consumption, which is calculated according to the following formula:

$$
\mathrm{SEA}=\frac{W_{L}}{V},
$$

where SEA is the specific energy absorption value $\left(\mathrm{J} / \mathrm{cm}^{3}\right)$ and $V$ is the specimen volume $\left(\mathrm{cm}^{3}\right)$.

Similarly, the ratio of breakage energy to incident energy is defined as the energy dissipation rate $(N)$ :

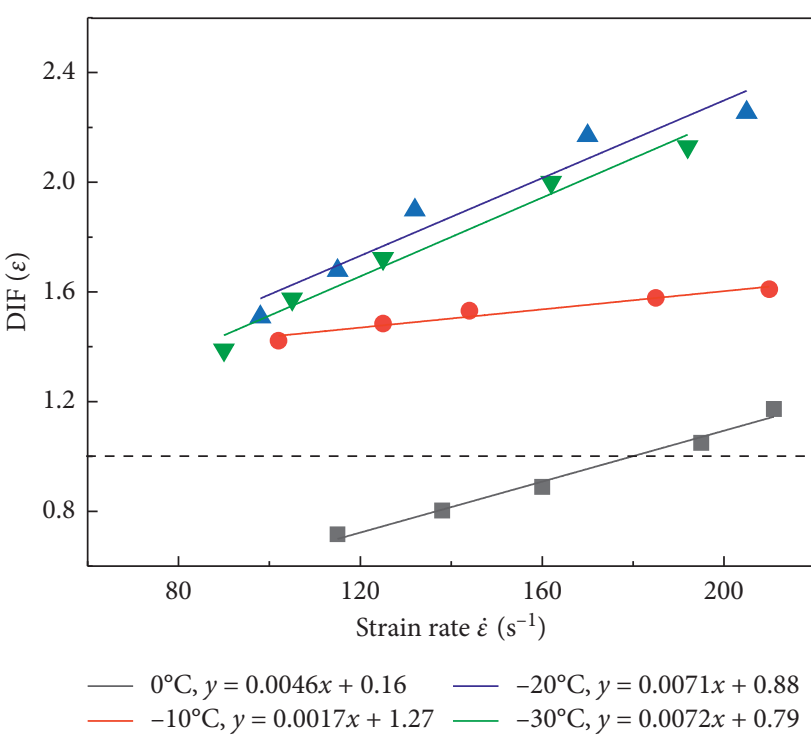

FIgURE 6: Relationship between DEIF and strain rate.

$$
N=\frac{W_{L}}{W_{I}} \times 100 \%
$$

According to the data obtained from the experiment, the specific values of various energies of saturated red sandstone under different freezing temperatures are calculated by formulas (3)-(6) and summarized in Table 4.

4.2. Energy Time-History Curve. Typical energy time-history curve is selected to analyze the energy change of frozen sandstone under impact, as shown in Figure 7.

According to the shape of energy time-history curve, the curve is divided into three stages: (1) the first stage $(0-40 \mu \mathrm{s})$ : in the initial stage of loading, the incident energy, reflected energy, transmitted energy, and absorbed energy are approximately a horizontal line, which is at the rising front, and there is almost no energy transfer in the specimen and the energy is less than $1.0 \mathrm{~J}$; (2) the second stage (40-155 $\mu \mathrm{s})$ : in the middle stage of loading, the incident energy and reflected energy increase linearly with time, increasing to $15.54 \mathrm{~J}$ and $12.11 \mathrm{~J}$, respectively; however, the transmitted energy and dissipation energy increase slightly; (3) the third stage $(155-200 \mu \mathrm{s})$ : in the later period of loading, after all the strain energy stored in the middle stage of loading is completely released, the whole energy tends to be constant and returns to the approximate horizontal state. 
TABLE 4: Summary of energy calculations.

\begin{tabular}{|c|c|c|c|c|c|c|c|c|c|}
\hline $\begin{array}{l}T \\
\left({ }^{\circ} \mathrm{C}\right) \\
\end{array}$ & $\begin{array}{l}\text { Incident } \\
\text { energy }(J)\end{array}$ & $\begin{array}{l}\text { Dissipated } \\
\text { energy }(J)\end{array}$ & $\begin{array}{c}\text { Dissipation rate } \\
(\%)\end{array}$ & $\begin{array}{l}\text { SEA } \\
\left(\mathrm{J} / \mathrm{cm}^{3}\right)\end{array}$ & $\begin{array}{c}T \\
\left({ }^{\circ} \mathrm{C}\right)\end{array}$ & $\begin{array}{l}\text { Incident } \\
\text { energy }(J)\end{array}$ & $\begin{array}{l}\text { Dissipated } \\
\text { energy }(J)\end{array}$ & $\begin{array}{c}\text { Dissipation rate } \\
(\%)\end{array}$ & $\begin{array}{l}\text { SEA } \\
\left(\mathrm{J} / \mathrm{cm}^{3}\right)\end{array}$ \\
\hline \multirow{5}{*}{0} & 13.7 & 2.4 & 17.5 & 0.0489 & \multirow{5}{*}{-10} & 14.0 & 1.5 & 10.7 & 0.0306 \\
\hline & 19.5 & 3.5 & 17.9 & 0.0713 & & 20.1 & 2.6 & 12.9 & 0.0529 \\
\hline & 24.7 & 4.9 & 19.8 & 0.0998 & & 23.8 & 3.4 & 14.3 & 0.0693 \\
\hline & 31.1 & 7.7 & 24.7 & 0.1569 & & 30.9 & 4.3 & 13.9 & 0.0876 \\
\hline & 37.8 & 9.2 & 24.3 & 0.1875 & & 38.2 & 5.3 & 13.9 & 0.1080 \\
\hline \multirow{5}{*}{-20} & 12.6 & 1.8 & 14.3 & 0.0367 & \multirow{5}{*}{-30} & 12.9 & 2.2 & 17.1 & 0.0448 \\
\hline & 19.4 & 2.8 & 14.4 & 0.0571 & & 18.8 & 2.9 & 15.4 & 0.0591 \\
\hline & 24.1 & 4.1 & 17.0 & 0.0836 & & 25.2 & 4.7 & 18.7 & 0.0958 \\
\hline & 32.0 & 5.7 & 17.8 & 0.1162 & & 30.9 & 6.3 & 20.4 & 0.1284 \\
\hline & 38.1 & 6.4 & 16.8 & 0.1304 & & 37.7 & 9.5 & 25.2 & 0.1936 \\
\hline
\end{tabular}

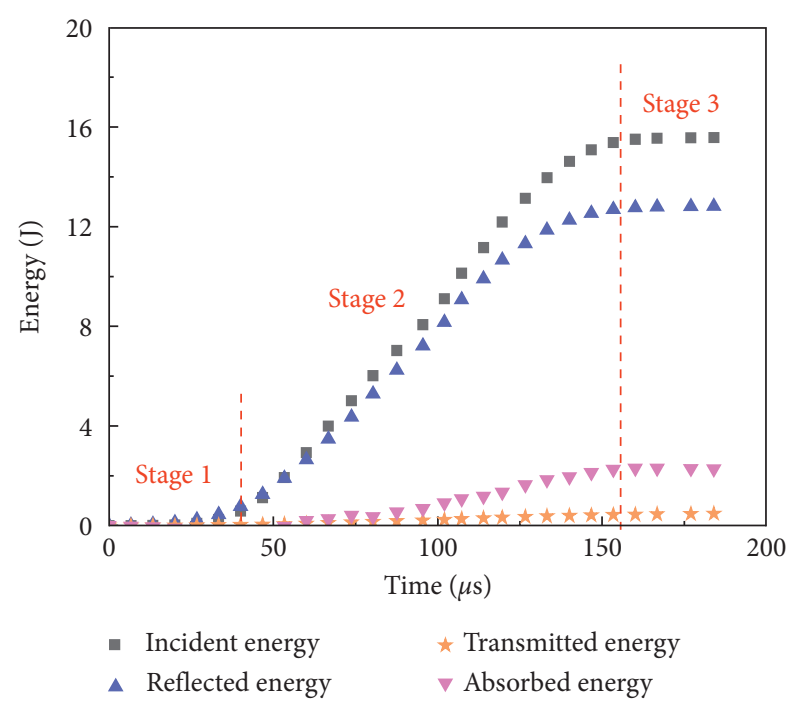

Figure 7: Energy time-history curve of saturated frozen sandstone under impact.

\section{Law of Energy Dissipation}

5.1. Strain Rate Effect of Energy Dissipation. Figure 8 shows the relationship between dissipation energy and strain rate of saturated red sandstone at different freezing temperatures. It can be seen that the dissipation energy increases linearly with the increase in strain rate. By comparing the slopes of the curves, it is found that the specimens at $0^{\circ} \mathrm{C}$ and $-30^{\circ} \mathrm{C}$ are more susceptible to strain rate than those at $-10^{\circ} \mathrm{C}$ and $-20^{\circ} \mathrm{C}$, especially at high strain rate.

Further analysis shows that when the strain rate is low, the incident energy in the elastic bar is small, which is basically converted into reflected energy and transmitted energy, and the energy absorbed by the specimen is very small, so the dissipated energy of the specimens at each temperature has little difference. With the increase in strain rate, the stress wave in the elastic bar will carry more energy to apply on the specimen, which will lead to the increase in dissipated energy for the derivation and expansion of internal fracture. The difference in dissipated energy between each temperature sample gradually appears, showing obvious correlation of strain rate.

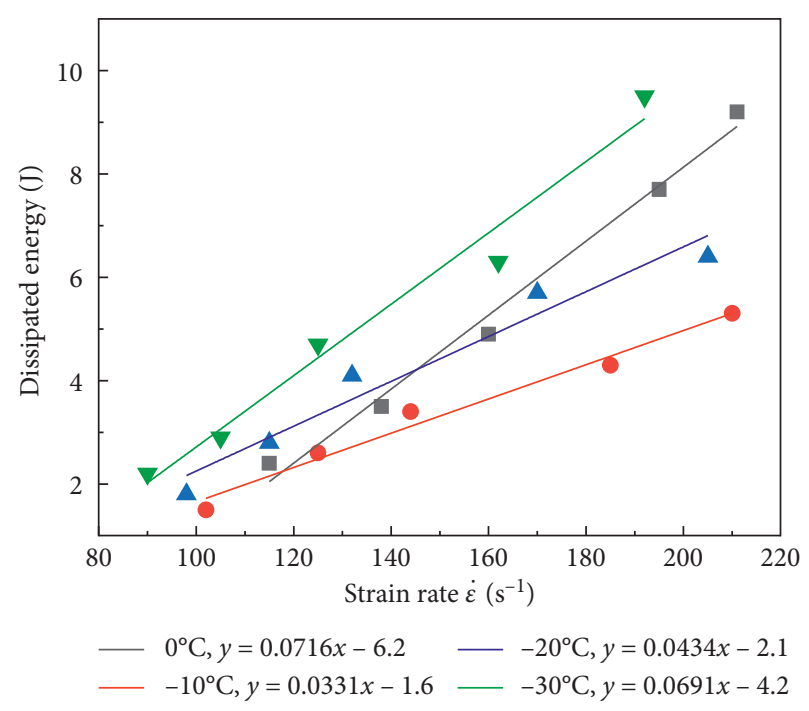

FIgURE 8: Relationship between dissipated energy and strain rate.

As shown in Figure 9, with the increase in strain rate, the energy dissipation rate of each temperature specimen does not show a significant increase or decrease trend but fluctuates within the range of $10 \%$ to $25 \%$. The discreteness of the data is large, and the strain rate is obviously independent.

At the same strain rate, the energy dissipation rate of specimens at $0^{\circ} \mathrm{C}$ and $-30^{\circ} \mathrm{C}$ is significantly higher than that at $-10^{\circ} \mathrm{C}$ and $-20^{\circ} \mathrm{C}$, and the difference gradually increases with the increase in strain rate. The reasons are summarized as follows: (1) on the one hand, due to the cold shrinkage of rock matrix and ice at $-10^{\circ} \mathrm{C}$ and $-20^{\circ} \mathrm{C}$, the integrity and impact resistance of the specimen are enhanced, but the deformation and failure will tend to be brittle while hardening, so the energy dissipation is less; (2) on the other hand, the low-temperature hardening effect is not obvious at $0^{\circ} \mathrm{C}$, so the specimen will absorb more energy for crack propagation and derivation. Due to the "frostbite" at $-30^{\circ} \mathrm{C}$, the rock will be destroyed along the main fracture, and the destruction process will consume more energy.

5.2. Temperature Effect of Energy Dissipation. Figure 10 shows the relationship between the specific energy 


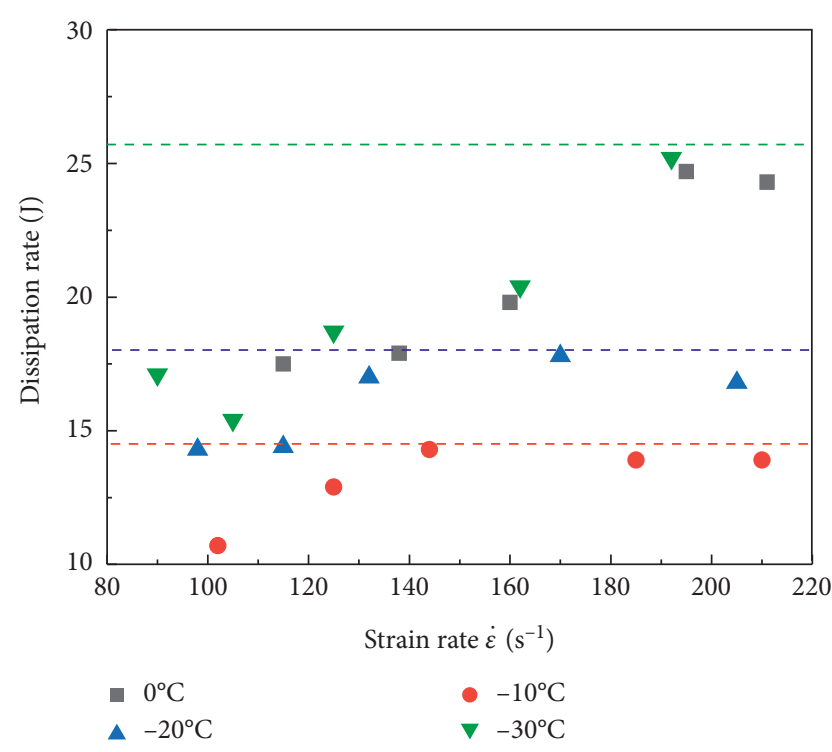

FIGURE 9: Relationship between energy dissipation rate and strain rate.

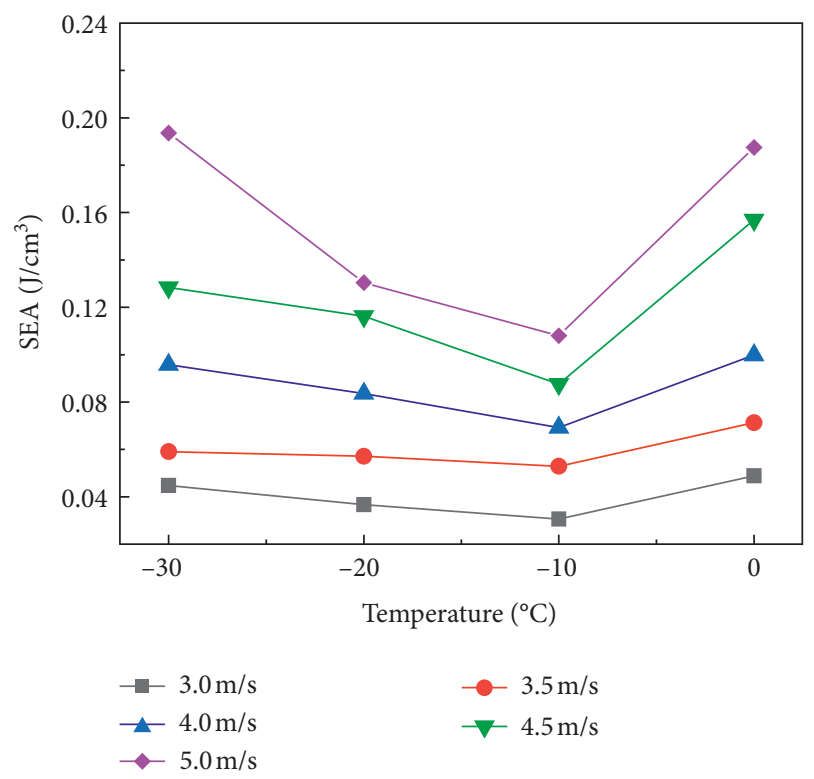

FIgURE 10: Relationship between SEA and temperature.

absorption value (SEA) and temperature of saturated frozen red sandstone under different impact velocities. It can be seen that, when the temperature is reduced from $0^{\circ} \mathrm{C}$ to $-10^{\circ} \mathrm{C}$, SEA decreases by $37.42 \%, 25.81 \%, 30.56 \%, 44.17 \%$, and $42.40 \%$, respectively, at the impact speed of $3.0 \mathrm{~m} / \mathrm{s}$ to $5.0 \mathrm{~m} / \mathrm{s}$. When the temperature drops from $-10^{\circ} \mathrm{C}$ to $-30^{\circ} \mathrm{C}$, the value of SEA increased in varying degrees. Under the impact velocity of $5.0 \mathrm{~m} / \mathrm{s}$, the value of SEA increased from $0.108 \mathrm{~J} / \mathrm{cm}^{3}$ to $0.194 \mathrm{~J} / \mathrm{cm}^{3}$, with an increase in $79.26 \%$.

The value of SEA changes suddenly at $-10^{\circ} \mathrm{C}$, and it can be inferred that the energy change from $0^{\circ} \mathrm{C}$ to $-10^{\circ} \mathrm{C}$ is discontinuous. The reason is mainly related to the water-ice phase change in the state of low temperature and water saturation. There is a water-ice phase change temperature point. After the temperature is reduced to this point, the bearing capacity of rock increases and the internal fracture is difficult to expand and derive. Therefore, the absorbed energy and dissipated energy are small. In the aspect of macroscopic, the value of SEA becomes smaller and the degree of fragmentation decreases.

Figure 11 shows the change in energy dissipation rate with temperature, which can reflect the influence of low temperature gradient on rock impact damage.

It can be seen from the figure that the energy dissipation rate of $-10^{\circ} \mathrm{C}$ specimen at each impact speed is less than other temperature gradients, which indicates that the development of the cracks of the sandstone is greatly restricted at $-10^{\circ} \mathrm{C}$, and the crack propagation is difficult. The energy dissipation rate of the specimen becomes smaller at the macrolevel. In the negative temperature range of $-10^{\circ} \mathrm{C}$ to $-30^{\circ} \mathrm{C}$, the energy dissipation rate increases gradually with the decrease in temperature, and the discreteness of data becomes larger, which shows that the low temperature has a significant effect on the energy dissipation of saturated sandstone.

\section{Macroscopic Failure Characteristics of Frozen Sandstone}

In order to compare the failure laws of frozen sandstone under different strain rates, the specimen at $-10^{\circ} \mathrm{C}$ is selected for the failure morphology analysis after impact, as shown in Figure 12.

It can be seen that the fragmentation degree of the rock gradually decreases with the increase in strain rate, which can be divided into the following three stages: (1) under the strain rate of $102 \mathrm{~s}^{-1} \sim 144 \mathrm{~s}^{-1}$, the energy absorbed by the specimen is low and large size fragments with the same height as the original specimens appear after the failure, which are mainly lamellar structure and split column. The broken degree of the specimens is relatively low, which belongs to the typical tensile failure. (2) At the strain rate of $185 \mathrm{~s}^{-1}$, the stress wave carries more energy on the specimen. The number of massive and granular fragments increased significantly, and the tensile failure gradually changed into shear failure. (3) When the strain rate increases from $185 \mathrm{~s}^{-1}$ to $210 \mathrm{~s}^{-1}$, the dissipation energy of rock for internal fracture derivation and propagation increases with the increase in strain rate, and the number of shear fracture surfaces in the broken block increases significantly, which belongs to the form of particle crushing failure.

Figure 13 shows the failure morphology of saturated red sandstone from $0^{\circ} \mathrm{C}$ to $-30^{\circ} \mathrm{C}$ under the impact velocity of $4.5 \mathrm{~m} / \mathrm{s}$.

It can be seen that sandstone suffers different degrees of damage under different freezing temperatures, and the difference is mainly reflected in the size, quantity, and failure form of the broken body:

(1) $0^{\circ} \mathrm{C}$ : the core part of the specimen is retained after impact, while the edge part is crushed completely. 


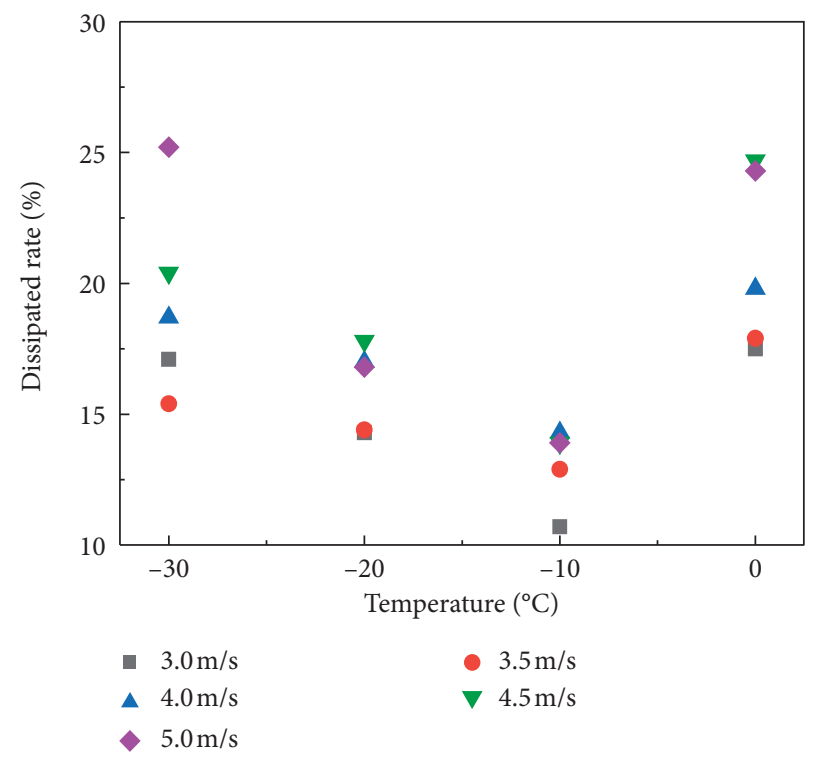

FIGURE 11: Relationship between energy dissipation rate and temperature.

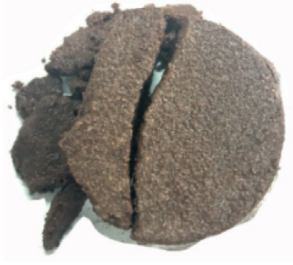

(a)

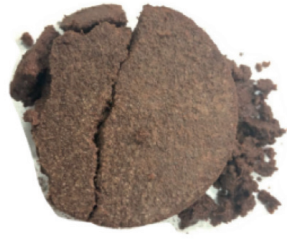

(b)

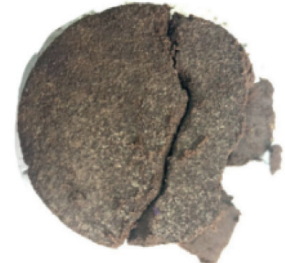

(c)

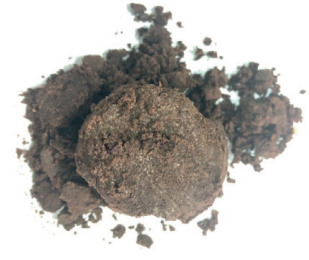

(d)

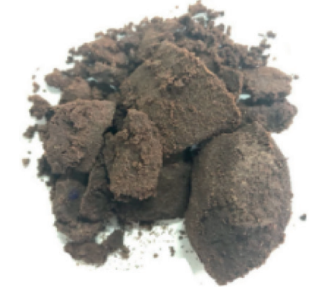

(e)

Figure 12: Typical failure modes of saturated frozen sandstone at $-10^{\circ} \mathrm{C}$ : (a) $102 \mathrm{~s}^{-1}$; (b) $125 \mathrm{~s}^{-1}$; (c) $144 \mathrm{~s}^{-1}$; (d) $185 \mathrm{~s}^{-1}$; (e) $210 \mathrm{~s}^{-1}$.

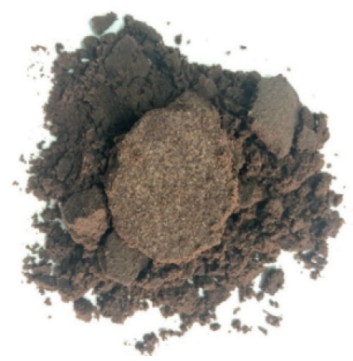

(a)

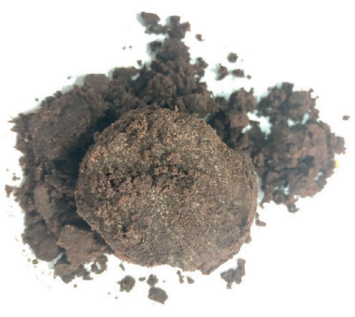

(b)

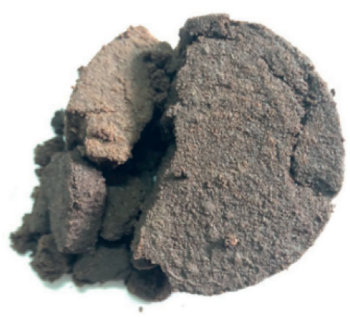

(c)

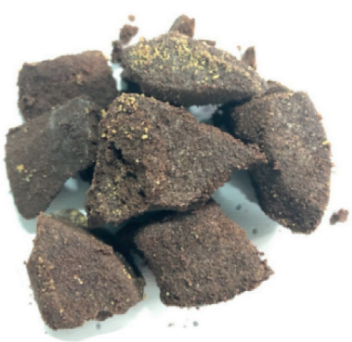

(d)

Figure 13: Failure modes of red sandstone at different temperatures: (a) $0^{\circ} \mathrm{C}$; (b) $-10^{\circ} \mathrm{C}$; (c) $-20^{\circ} \mathrm{C}$; (d) $-30^{\circ} \mathrm{C}$.

(2) $-10^{\circ} \mathrm{C}$ : due to the low-temperature hardening effect, the crushing degree of the specimen is reduced compared to $0^{\circ} \mathrm{C}$. The residual volume of the core of the specimen becomes larger and the degree of edge breakage decreases after destruction.

(3) $-20^{\circ} \mathrm{C}$ : a large volume of cylindrical split fragments and a small amount of conical blocks exist at the same time after the failure of the specimen. The degree of fragmentation is significantly reduced, the low-temperature hardening effect is obvious, and the tensile failure was dominant.

(4) $-30^{\circ} \mathrm{C}$ : after the failure, the volume of fragments decreases, the number of shear fracture surfaces increases, and the crushing degree intensifies. The crushing shape is a massive cone. Compared with $-20^{\circ} \mathrm{C}$, the effect of low-temperature frostbite deterioration is obvious. 


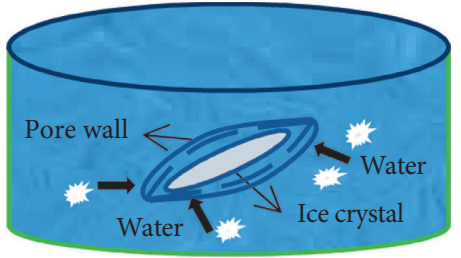

(a)

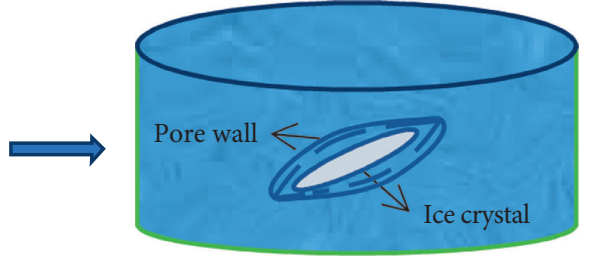

(b)

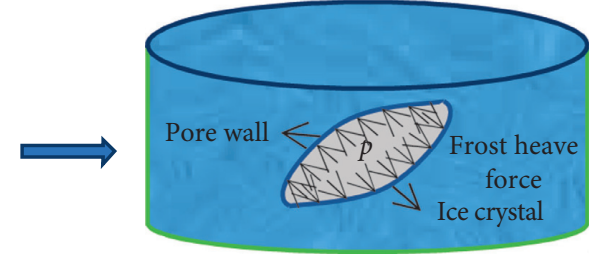

(c)

Figure 14: Diagram of water migration in the sample and the effect of ice on the pore wall: (a) migration of water; (b) frozen shrinkage; (c) frozen shrinkage and frost heave.

\section{Micromechanism Analysis}

The above phenomena are analyzed from the perspective of microscopic mechanism. At $0^{\circ} \mathrm{C}$, the increase in strength caused by cold shrinkage of the rock matrix is greater than the volume expansion caused by water-ice phase change, but the improvement of the performance of the sandstone is limited. In the temperature range of $-10^{\circ} \mathrm{C}$ to $-20^{\circ} \mathrm{C}$, the shrinkage speed of the rock matrix is slightly greater than ice, the microcracks and microdefects caused by water-ice phase change will close or disappear with the shrinkage of mineral particles, and the strength of rock will increase with the decrease in temperature. At $-30^{\circ} \mathrm{C}$, the shrinkage rate of rock matrix is significantly higher than the ice medium, and there are significant differences in the shrinkage rate of each component medium of frozen rock. A large number of secondary defects will be generated inside the frozen rock and the interface between the matrix and the ice.

From the above analysis, it can be seen that pore water plays an important role in the change in mechanical properties of frozen sandstone. Figure 14 shows the change in pore water and ice in the rock during the continuous freezing process.

In the early stage of freezing $\left(0\right.$ to $\left.-20^{\circ} \mathrm{C}\right)$, the water in the rock will migrate to the free space in the pores and gradually freeze into ice crystals to fill the pores. At this time, there is no macroscopic frost heave deformation, and the rock medium does not bear the frost heaving force, which is manifested as freezing shrinkage. At $-30^{\circ} \mathrm{C}$, the free space in the pores is completely occupied by ice crystal, and the expansion of ice dominates. The pore wall will be subjected to the compression effect of frost heaving force, and the medium skeleton will expand and deform under the action of frost heaving force, which appears as frost heave. As the porosity and permeability of the specimen gradually decrease with the occurrence of frost heave, the migration of water will stop, the pore ice will not increase any more, and the pore damage inside the rock is in a steady state. At this time, part of the unfrozen water still exists in the pores due to the interface effect [35-39], which will migrate to the secondary defects caused by the water-ice phase change and intensify the frost heave damage of these parts.

\section{Conclusion}

(1) The peak stress and peak strain of frozen sandstone increase with the increase in strain rate and increase with the decrease in freezing temperature, which shows significant strain rate strengthening and lowtemperature hardening effect. At $-30^{\circ} \mathrm{C}$, sandstone appears as "frostbite" under high strain rate, and its mechanical properties are significantly reduced.

(2) The strain rate sensitivity of dynamic stress increase factor (DIF) is negatively correlated with temperature. Water-ice phase change and the difference in cold shrinkage rate of rock matrix under strong impact loading will degrade rock performance together, so DIF is less than 1 . From $-10^{\circ} \mathrm{C}$ to $-30^{\circ} \mathrm{C}$, low-temperature hardening effect and lateral inertia effect improve the deformation resistance of the specimen together during the impact process, and DEIF is always be greater than 1 .

(3) At the same temperature, with the increase in strain rate, the energy dissipation rate fluctuates within the range of $10 \%$ to $25 \%$, which is highly discrete, showing significant strain rate independence, and the failure model gradually changes from tensile failure to shear failure and particle crushing failure. At the same strain rate, with the decrease in temperature, the specific energy absorption value changes abruptly at $-10^{\circ} \mathrm{C}$, and the failure form gradually changes from particle crushing failure to tensile failure and shear failure.

(4) The difference in mechanical properties of sandstone is mainly caused by water-ice phase change and the difference in cold shrinkage rate of the frozen rock medium. When the temperature drops from $0^{\circ} \mathrm{C}$ to $-20^{\circ} \mathrm{C}$, the water migrates to the pores of frozen rock and freezes into ice gradually, resulting in frozen shrinkage. At $-30^{\circ} \mathrm{C}$, the free space of pores is completely occupied by ice crystals, and the migration of water will stop, leading to frost heave.

\section{Data Availability}

The data used to support the findings of this study are included within the article.

\section{Conflicts of Interest}

The authors declare that there are no conflicts of interest regarding the publication of this paper.

\section{Acknowledgments}

The work was supported by the National Natural Science Foundation of China (nos. 51404193 and 41702339), the 
Shaanxi Provincial Natural Science Foundation (nos. 2018JQ4026 and S2015YFJQ1194), and the China Postdoctoral Fund (no. 2015M572581). The authors thank the Xi'an University of Science and Technology for providing the experiment conditions.

\section{References}

[1] G. S. Yang, J. M. Xi, H. J. Li, L. Chen, and T. Lv, "Experimental study on mechanical properties of soft rock of freezing wall in shaft of coal mine," Chinese Journal of Underground Space and Engineering, vol. 8, no. 4, pp. 690-697, 2012.

[2] G. S. Yang, J. M. Xi, Z. J. Wang, L. Chen, and H. J. Li, "Study on rock mechanical properties of frozen wall of main shaft in Hujiahe coal mine," Journal of China Coal Society, vol. 35, no. 4, pp. 565-570, 2010.

[3] G. S. Yang, Y. Wei, Y. J. Shen et al., "Mechanical behavior and strength forecast model of frozen saturated sandstone under triaxial compression," Journal of Rock Mechanics and Geotechnical Engineering, vol. 38, no. 4, pp. 683-694, 2019.

[4] G. S. Yang, C. H. Zhang, and Y. G. Tian, "Numerical simulation and analysis of moisture-heat coupling for soft rock tunnel in cold regions," Rock and Soil Mechanics, vol. 27, no. 8, pp. 1258-1262, 2006.

[5] W. M. Wang, Z. H. Zhao, and L. Wang, "Elastic-plastic damage analysis for weakly consolidated surrounding rock regarding stiffness and strength cracking," Journal of Mining and Safety Engineering, vol. 30, no. 5, pp. 679-685, 2013.

[6] W. M. Wang, L. Wang, and C. Q. Dai, "Frozen wall deformation analysis in weakly cemented soft rock based on layered calculation of strength," Journal of Rock Mechanics and Geotechnical Engineering, vol. 30, no. 2, pp. 4110-4116, 2011.

[7] Z. H. Zhao, W. M. Wang, X. Gao, and X. J. Yan, "Damage behavior of weakly consolidated soft mudstone under triaxial compression," Journal of Zhejiang University (Engineering), vol. 48, no. 8, pp. 1399-1405, 2014.

[8] Z.-h. Zhao, W.-m. Wang, C.-q. Dai, and J.-x. Yan, "Failure characteristics of three-body model composed of rock and coal with different strength and stiffness," Transactions of Nonferrous Metals Society of China, vol. 24, no. 5, pp. 15381546, 2014.

[9] B. Liu, N. Lian, D. Y. Li, S. Wang, and Y. C. Liu, "Strength test on frozen cracked red sandstone combined with ice," Journal of China Coal Society, vol. 41, no. 4, pp. 843-849, 2016.

[10] B. Liu, Y. J. Ma, H. L. Sheng et al., "Experiments on mechanical properties of Cretaceous red sandstone after freezethaw process," Rock and Soil Mechanics, vol. 40, no. 1, pp. 161-171, 2019.

[11] B. Liu, Y. J. Ma, H. L. Sheng, H. L. Deng, Q. Han, and Y. J. Cao, "Experimental study on mechanical properties of Cretaceous red sandstone under different freezing temperatures and confining pressures," Journal of Rock Mechanics and Geotechnical Engineering, vol. 38, no. 3, pp. 455-466, 2019.

[12] Z. Q. Chen, T. B. Li, G. Q. Chen, and C. C. Ma, "Experimental study on energy evolution of sandstone under different stress paths," Engineering Mechanics, vol. 33, no. 6, pp. 120-128, 2016.

[13] Y. Shen, Y. Yang, G. Yang et al., "Damage characteristics and thermo-physical properties changes of limestone and sandstone during thermal treatment from $-30^{\circ} \mathrm{C}$ to $1000^{\circ} \mathrm{C}$, " Heat and Mass Transfer, vol. 54, no. 11, pp. 3389-3407, 2018.

[14] Y.-j. Shen, Y.-z. Wang, X.-d. Zhao, G.-s. Yang, H.-l. Jia, and T.-1. Rong, "The influence of temperature and moisture content on sandstone thermal conductivity from a case using the artificial ground freezing (AGF) method," Cold Regions Science and Technology, vol. 155, no. 11, pp. 149-160, 2018.

[15] B. Y. Zhao, D. Y. Liu, T. Z. Huang, W. Huang, and W. Liu, "Mechanical behavior of red sandstone under incremental uniaxial cyclical compressive and tensile loading," Shock and Vibration, vol. 2017, no. 10, Article ID 4350437, 10 pages, 2017.

[16] Y. Sun, Y. Yang, and M. Li, "Dynamic behavior and fatigue damage evolution of sandstone under uniaxial cyclic loading," Shock and Vibration, vol. 2020, no. 7, p. 9, 2020.

[17] X. B. Li, Z. L. Zhou, Z. Y. Ye et al., "Study of rock mechanical characteristic under coupled static and dynamic loads," Journal of Rock Mechanics and Geotechnical Engineering, vol. 27, no. 7, pp. 1387-1395, 2008.

[18] X. B. Li, Y. J. Zuo, and C. D. Ma, "Failure criterion of strain energy density and catastrophe theory analysis of rock subjected to static-dynamic coupling loading," Journal of Rock Mechanics and Geotechnical Engineering, vol. 24, no. 16, pp. 2814-2824, 2005.

[19] X. B. Li, F. Q. Gong, K. Gao, and T. B. Yin, "Test study of impact failure of rock subjected to one-dimensional coupled static and dynamic loads," Journal of Rock Mechanics and Geotechnical Engineering, vol. 29, no. 2, pp. 251-260, 2010.

[20] S. H. Liu, J. Y. Xu, P. Wang, and G. X. Zhang, "Mechanical and ultrasonic analysis on damage of sandstone under cyclical impact loading with confining pressure," Journal of Vibration and Shock, vol. 34, no. 1, pp. 190-194, 2015.

[21] S. H. Liu, J. Y. Xu, P. Wang, and S. Liu, "A SHPB experimental study and microscomic analysis of freeze-thaw red sandstone," Journal of Vibration and Shock, vol. 36, no. 20, pp. 203-209, 2017.

[22] Q. Y. Ma, P. Y. Yu, and P. Yuan, "Experimental study on creep properties of deep siltstone under cyclic wetting and drying," Journal of Rock Mechanics and Geotechnical Engineering, vol. 37, no. 3, pp. 593-600, 2018.

[23] P. Yuan and Q. Y. Ma, "Split Hopkinson pressure bar tests on sandstone in coalmine under cyclic wetting and drying," Rock and Soil Mechanics, vol. 34, no. 9, pp. 2557-2562, 2013.

[24] Q. Ma, D. Ma, and Z. Yao, "Influence of freeze-thaw cycles on dynamic compressive strength and energy distribution of soft rock specimen," Cold Regions Science and Technology, vol. 153, no. 9, pp. 10-17, 2018.

[25] Y. Yang, R. S. Yang, J. G. Wang, S. Z. Fang, and N. N. Zhang, "Experimental study on dynamic mechanical properties of red sandstone under low temperature," Journal of China Coal Society, vol. 43, no. 4, pp. 967-975, 2018.

[26] R. Yang, S. Fang, D. Guo, W. Li, and Z. Mi, "Study on dynamic tensile strength of red sandstone under impact loading and negative temperature," Geotechnical and Geological Engineering, vol. 37, no. 5, pp. 4527-4537, 2019.

[27] R. Yang, S. Fang, W. Li, Y. Yang, and Z. Yue, "Experimental study on the dynamic properties of three types of rock at negative temperature," Geotechnical and Geological Engineering, vol. 37, no. 1, pp. 455-464, 2019.

[28] R. L. Shan, Y. W. Song, L. W. Song et al., "Time dependent damage model of northwest artificial frozen red sandstone under dynamic loading," Journal of China Coal Society, vol. 43, no. 1, pp. 118-123, 2018.

[29] R. L. Shan, L. Zhang, H. Yang, J. X. Zhang, and Z. M. Guo, "Experimental study of freeze-thaw properties of saturated red sandstone," Journal of China University of Mining \& Technology (Social Science), vol. 45, no. 5, pp. 923-929, 2016.

[30] R. L. Shan, Y. W. Song, L. W. Song, and B. Yao, "Dynamic property tests of frozen red sandstone using a split hopkinson 
pressure bar," Earthquake Engineering and Engineering Vibration, vol. 18, no. 3, pp. 511-519, 2019.

[31] B. Du, H. B. Bai, and G. M. Wu, "Dynamic compression properties and deterioration of red-sandstone subject to cyclic wet-dry treatment," Advances in Civil Engineering, vol. 2019, no. 4, Article ID 1487156, 11 pages, 2019.

[32] T. Rabczuk and T. Belytschko, "Cracking particles: a simplified meshfree method for arbitrary evolving cracks," International Journal for Numerical Methods in Engineering, vol. 61, no. 13, pp. 2316-2343, 2004.

[33] H. Ren, X. Zhuang, and T. Rabczuk, "Dual-horizon peridynamics: a stable solution to varying horizons," Computer Methods in Applied Mechanics and Engineering, vol. 318, pp. 762-782, 2017.

[34] N. Vu-Bac, T. Lahmer, X. Zhuang, T. Nguyen-Thoi, and T. Rabczuk, "A software framework for probabilistic sensitivity analysis for computationally expensive models," $A d$ vances in Engineering Software, vol. 100, no. 6, pp. 19-31, 2016.

[35] J. S. Walder and B. Hallet, "A theoretical model of the fracture of rock during freezing," Geological Society of America Bulletin, vol. 96, no. 3, pp. 336-346, 1985.

[36] R. R. Gilpin, "A model for the prediction of ice lensing and frost heave in soils," Water Resources Research, vol. 16, no. 5, pp. 918-930, 1980.

[37] H. L. Jia, S. Ding, Y. Wang, Z. Fan, and G. S. Yang, "An NMRbased investigation of pore water freezing process in sandstone," Cold Regions Science and Technology, vol. 168, Article ID 102893, 2019.

[38] Z. H. Zhao, M. Z. Zhang, Q. Ma, and B. S. Chen, "Deviation effect of coaxiality on the rock Brazilian split," Advances in Mathematical Physics, vol. 2020, no. 1, Article ID 5782457, 8 pages, 2020.

[39] M. Wen, J. Y. Xu, H. Y. Wang, X. Y. Fang, and G. H. Zheng, "Fractography analysis of sandstone failure under low temperature-dynamic loading coupling effects," Chinese Journal of Rock Mechanics and Engineering, vol. 36, no. S2, pp. 3822-3830, 2017. 